\title{
YAC-Based STS-Content Mapping
}

National Cancer Institute

\section{Source}

National Cancer Institute. YAC-Based STS-Content Mapping. NCI Thesaurus. Code C19654.

YAC based content mapping is a clone-based physical genome mapping strategy. Content mapping is done by ordering sequence tagged sites (STS), regions of the genome which can be uniquely identified, and YAC (Yeast Artificial Chromosome) clone ends along the chromosome, based on the STS content of each clone, for constructing a composite map that represents the linear order and position of mapping landmarks along the genome. 